\title{
Survival rate of implants placed in augmented sinuses in a post-graduate
}

implant program

Cebola $\mathrm{A}^{*}$; Pereira MC*; Lagrange $\mathrm{J}^{* *}$; Chen $\mathrm{A}^{* *}$; Francisco $\mathrm{H}^{* * *}$; Caramês J****

*Resident at Post-graduation Course in Oral Surgery, University of Lisbon Faculty of Dental Medicine

**Assistant Lecturer at the Oral Surgery and Implant Dentistry Department at University of Lisbon Faculty of Dental Medicine

***Assistant Professor at the Oral Surgery and Implant Dentistry Department at University of Lisbon Faculty of Dental Medicine

****Full Professor at the Oral Surgery and Implant Dentistry Department at University of Lisbon Faculty of Dental Medicine

\section{BACKGROUND}

The concept of maxillary sinus elevation was first introduced in 1976 by Tatum at a Congress of Implantology in Alabama. This procedure is indicated in implant rehabilitations in the posterior region of the maxilla, when the residual bone height does not allow the placement of dental implants (Riben \& Thor, 2012, Menicucci, et al., 2013). The current surgical principles and techniques are similar to those presented by Tatum in 1976, and later published by Boyne and James in 1980 (Riben \& Thor, 2012; Boyne \& James, 1980).

The classical approach begins with a full thickness incision at the level of the alveolar ridge followed by flap elevation. A bone window is prepared with subsequent elevation of the membrane. After elevation of the sinus membrane, the space created between the bony ridge and the raised Schneider's membrane is filled by a bone substitute (Menicucci, et al., 2013; Rickert, et al., 2012).

With regard to implant placement, they may be placed concomitantly with the elevation of the sinus or the implant may be placed posteriorly, in a second surgical phase, after a healing period (Schmitt, et al., 2013; Elias, et al., 2012).

\section{AIM/HYPOTHESIS}

To evaluate the survival rate of implants placed in the posterior maxilla, using the lateral antrostomy technique at the University of Lisbon, College of Dentistry - Implantology Program.

\section{MATERIALS AND METHODS}

Retrospective cohort. Evaluation of dental records and x-rays was performed to assess implant survival. Smoking status and diabetes were recorded and considered as covariates. Follow up periods was also analyzed. Survival analysis with Cox Regression Model, Chi-square, relative risk, absolute risk increase and number needed to harm were used as appropriated, confidence level was set at $95 \%$. Alpha was set at 0,05.

\section{RESULTS}

This study included 52 implants from 25 patients with age ranging from 32-85 years old. Of the 25 patients: 8 were male and 17 female (Table I); 6 were smokers and 19 non-smokers (Table II); 1 patient was diabetic (Table III). The follow-up period for this study was between 9-75 months (Plot I). The survival rate of this preliminary retrospective study was $100 \%$.

\begin{tabular}{c|ccc}
\hline & \multicolumn{3}{|c}{ Gender } \\
\hline & Frequency & Percentage & Valid Percentage \\
\hline Female & 8 & 32 & 32 \\
\hline Male & 17 & 68 & 68 \\
\hline Total & 25 & 100 & 100 \\
\hline
\end{tabular}

Table I - Gender - Frequency and Percentage

\begin{tabular}{c|ccc}
\hline & \multicolumn{3}{|c}{ Smoker } \\
\hline & Frequency & Percentage & Valid Percentage \\
\hline No & 19 & 76 & 76 \\
\hline Yes & 6 & 24 & 24 \\
\hline Total & 25 & 100 & 100 \\
\hline
\end{tabular}

Table II - Smoker - Frequency and Percentage

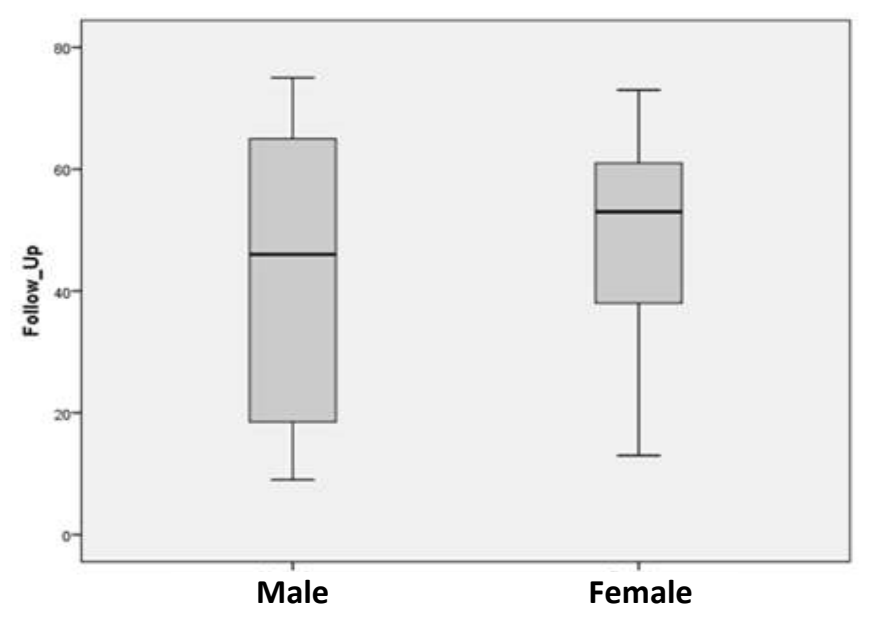

Plot I- Follow-up Box-plot

\section{CONCLUSION AND CILINCAL IMPLICATIONS}

Maxillary sinus augmentation is a predictable technique for the placement of implants in posterior edentate maxilla where bone volume is short. Even though the sample is small, this study presents an implant survival rate similar to the one described in the literature. In areas of the posterior maxilla where bone volume is low, implant rehabilitation with maxillary sinus augmentation can be performed with a high degree of predictability.

Boyne PJ, James RA. Grafting of the maxillary sinus floor autogenous marrow and bone. J Oral Surg. 1980; 38 (8), 613-6. Cabezas-Mojón J, Barona-Dorado C, Gómez-Moreno G, Fernández-Cáliz F, MartínezGonzález JM. Meta-analytic study of implant survival following sinus augmentation. Med Oral Patol Oral Cir Bucal. 2012; 17(1), 35-39.Cabbar F, Güler N, Kürkcü M, Iseri U, Sençift K. The effect of bovine bone graft with or without platelet-rich plasma on maxillary sinus augmentation. J Oral Maxillofac Surg. 2011; 69(10), 2537-2547.Esposito M, Grusovin MG, Coulthard P, Worthington HV. The efficacy of various bone augmentation procedures for dental implants: a Cochrane systematic review of randomized controlled clinical trials. Int J Oral Maxillofac Implants. 2006; 21(5), 696-710. Esposito M, Grusovin MG, Kwan S, Worthington HV, Coulthard P. Interventions for replacing missing teeth: bone augmentation techniques for dental implant treatment. Cochrane Database Syst Rev. 2008; Vol 3. Esposito M, Grusovin MG, Rees J, Karasoulos D, Felice P, Alissa R, Worthington H, Coulthard P. Effectiveness of sinus lift procedures for dental implant rehabilitation: a Cochrane systematic review. Eur J Oral Implantol. 2010; 3(1), 7-26. Esposito M, Grusovin MG, Rees J, Karasoulos D, Felice P, Alissa R, Worthington HV, Coulthard P. Interventions for replacing missing teeth: augmentation procedures of the maxillary sinus. Cochrane Database Syst Rev. 2010; vol. 17. Del Fabbro M, Corbella S, Weinstein T, Ceresoli V, Taschieri S. Implant survival rates after osteotome-mediated maxillary sinus augmentation: a systematic review. Clin Implant Dent Relat Res. 2012; 14(Suppl. 1), e159-e16. Lee J, Jin S, Ko Y, Park J. Evaluation of anatomical considerations in the posterior maxillae for sinus augmentation. World Journal of Clinical Cases. 2014; 2(11), 683-88. Menicucci G, Mussano F, Schierano G, Rizzati A, Aimetti M, Gassino G, Traini T, Carossa S. Healing properties of implants inserted concomitantly with anorganic bovine bone. A histomorphometric human study. Aust Dent J. 2013; 58(1), 57-66. 